\title{
Epilepsy and insular Grade II gliomas: an interdisciplinary point of view from a retrospective monocentric series of 46 cases
}

\author{
Luc Taillandier, M.D., Ph.D., ${ }^{1}$ and Hugues Duffau, M.D., Ph.D. ${ }^{2,3}$ \\ ${ }^{1}$ Neuro-oncology Unit, Department of Neurology, Hôpital Central, Centre Hospitalier Universitaire de \\ Nancy; ${ }^{2}$ Department of Neurosurgery, Hôpital Gui de Chauliac; and ${ }^{3}$ Institut National de la Santé et de \\ la Recherche Médicale U888, Hôpital de la Colombière, Centre Hospitalier Universitaire de Montpellier, \\ France
}

Object. There are few data in the literature concerning a multimodal approach to insular WHO Grade II gliomas (GIIGs) and the control of epilepsy after treatment. In this paper, the authors describe a monocentric series of 46 cases in which patients underwent various sequential treatments for insular GIIGs. On the basis of global results with regard to epilepsy, the respective interests in the various treatments are discussed.

Methods. Available data on 46 patients harboring insular GIIGs were extracted from a local database of 288 GIIGs. The various therapeutic sequences were analyzed in parallel with the course of seizure frequency.

Results. Despite the usual difficulties with seizure quantification in retrospective studies, the authors showed that 1) the negative course of seizure frequency was mostly connected to tumor progression, 2) surgery almost always had a favorable effect on epilepsy, and 3) chemotherapy had a mostly favorable effect with acceptable tolerance. The authors were unable to draw conclusions about the role of radiotherapy given the too few cases.

Conclusions. This extensive experience with insular GIIGs tends to confirm interest in their surgical removal and supports interest in chemotherapy from an epileptological point of view. (DOI: 10.3171/2009.6.FOCUSO9102)

\section{Key Words - World Health Organization Grade II glioma - chemotherapy • low-grade glioma $\bullet$ insula $\bullet$ seizure $\bullet$ epilepsy $\bullet$ surgery}

$\mathrm{E}$ PILEPSY is a common complication in patients with primary brain tumors. ${ }^{39,40,77,78}$ Gliomas represent the majority of primitive tumors of the brain, with GIIGs making up 15\%; ${ }^{4}$ insular gliomas make up $15 \%$ of the WHO Grade II lesions (Réseau d'Etude des Gliomes databank).

The category of GIIGs is one of the most epileptogenic tumor groups; that is, it is the main symptom in up to $80 \%$ of patients with GIIGs. Intractable forms of epilepsy are observed in $\sim 10$ to $20 \%$ of cases. ${ }^{3,67,711,16,21,32,33,48,53,54,57,63,79,85}$ The precise mechanisms involved in the etiology of epilepsy remain globally unknown, ${ }^{33,37,44,64}$ and treatment strategies are still matters for discussion.

Surgery is probably one of the domains with the most development in the last few years. The approach is nevertheless technically difficult and reserved for specialized teams. Recent series have been rare. ${ }^{22,23,27,45,59,66,69,76,84,86}$ Furthermore, there is no consensus regarding the optimal type of surgery, for example, lesionectomy alone or

\footnotetext{
Abbreviations used in this paper: $\mathrm{AED}=$ antiepilepsy drug; $\mathrm{BI}=$ bevacizumab + irinotecan; GIIG = WHO Grade II glioma; PCV = procarbazine + lomustine $(\mathrm{CCNU})+$ vincristine; $\mathrm{TMZ}=$ temozolomide; $\mathrm{WS}=$ wait and see.
}

lesionectomy combined with the removal of surrounding epileptogenic cortex. The majority of concerned teams have reported favorable epileptological results in $\sim 80 \%$ of cases with or without the removal of mesiotemporal structures. ${ }^{66,70,84,86}$

Data concerning radiotherapy are exceptional. ${ }^{68}$ Moreover, to our knowledge, there are no specific data regarding the impact of chemotherapy or combining the strategies of surgery and chemotherapy in the control of epilepsy.

We here present a retrospective study undertaken at one French center engaged in the Réseau d'Etude des Gliomes (Glioma Study Network). We estimated the rate of seizures in a series of 46 patients with insular GIIGs and the effect of combined treatments on epilepsy.

\section{Methods}

We retrospectively reviewed available data in all cases of insular GIIGs in adults from a database at the university hospital in Nancy, France, containing 288 patients with WHO GIIGs. The insular glioma location was categorized using the classification of Yaşargil et al. ${ }^{84} \mathrm{Ac}-$ cording to this scheme, Type 3 tumors are restricted to 
TABLE 1: Summary of initial data in 22 patients who did not undergo surgery*

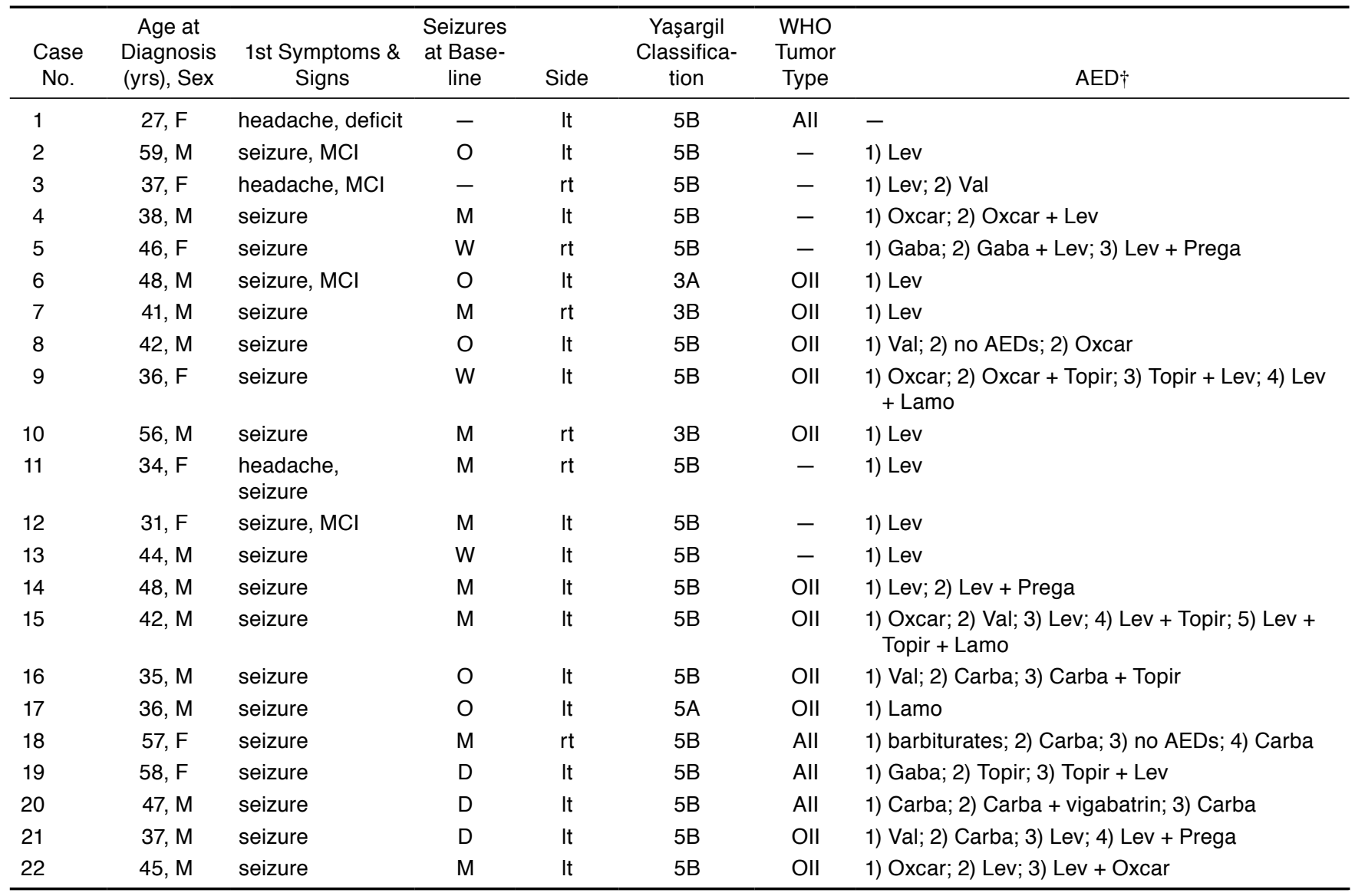

* All = astrocytoma Type II; Carba = carbamazepine; D = daily; Gaba = gabapentin; Lamo = lamotrigine; Lev = levetiracetam; M = monthly; $\mathrm{MCl}=$ mild cognitive impairment; $\mathrm{O}=$ occasionally; OII = oligodendroglioma Type II; Oxcar = oxcarbazepine; Prega = pregabalin; Topir = topiramate; $\mathrm{Val}=$ valproate; $\mathrm{W}=$ weekly; $-=$ not applicable.

$\dagger$ Numbering corresponds to the succession of therapeutic sequences.

the insula or parts of it (Type 3A) or may include the corresponding opercula (Type 3B). In addition to the insula and opercula, Type 5 tumors involve 1 or both paralimbic orbitofrontal and temporopolar areas, either without (Type 5A) or with (Type 5B) parts of the limbic system.

Baseline quantification of epilepsy was predicated on a simple classification distributing seizures into 4 categories as transcribed in our database: daily, weekly, monthly, or occasional. The evolution of seizure frequency was categorized using the Engel criteria: ${ }^{28} \mathrm{EI}=$ seizure free or auras only, EII = infrequent seizures, EIII = worthwhile improvement in seizure frequency or severity, and EIV = no significant improvement.

\section{Results}

Forty-six of 288 GIIG cases were included in our analysis. Twenty-four patients benefited from a surgical procedure, and 22 did not undergo surgery. The epileptological and treatment characteristics of the 46 patients are summarized in Tables 1-4. Data concerning chemotherapy are summarized in Table 5.

\section{Nonsurgical Population}

Clinical Data. The patients who did not undergo surgery consisted of 14 men and 8 women, ranging in age from 27-59 years (mean 42 years). Sixteen gliomas involved the dominant left hemisphere and 6 the nondominant right side. Three patients reported intense headaches; and 4, mild cognitive impairment. All but 1 (light paresis) preoperative neurological examination were normal.

Radiological Data. Pretherapeutic MR imaging revealed, according to the classification of Yaşargil et al., ${ }^{84}$ the following glioma locations: 1 patient, Type 3A; 2 patients, Type 3B; 1 patient, Type 5A; and 18 patients, Type $5 \mathrm{~B}$.

Neuropathological Data. The neuropathological examination led to the diagnosis of 4 WHO Grade II astrocytomas and 11 WHO Grade II oligodendrogliomas. Seven patients had no neuropathological confirmation of their lesions (noncontributive biopsy findings or no biopsy procedure because of the initial WS period).

Oncological Strategies. From an oncological point of 
TABLE 2: Seizure evolution in 22 patients who did not undergo surgery*

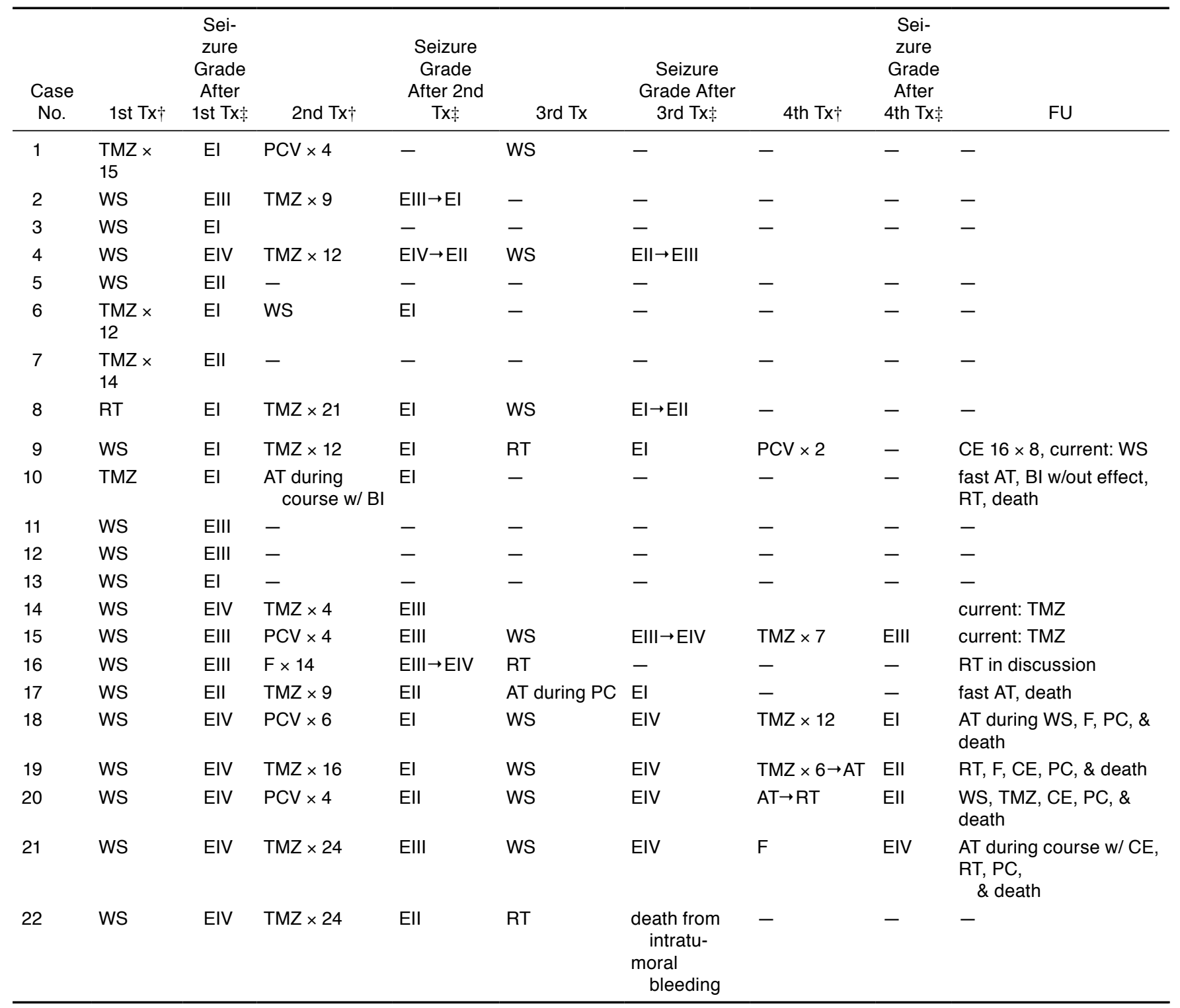

* AT = anaplastic transformation; $\mathrm{CE}=$ carboplatin + etoposide; $\mathrm{F}=$ fotemustine; $\mathrm{FU}=$ follow-up; $\mathrm{PC}=$ palliative care; $\mathrm{RT}=$ radiotherapy.

$\dagger$ Number of cycles of chemotherapy indicated by the number following the multiplication sign.

$\ddagger$ Engel classification: EI = seizure free; EII = occasional seizures; EIII =improvement in seizures but remain present; EIV = no modification or escalation in seizures.

view, various strategies were considered. Among the firstline strategies were 17 cases of close monitoring (WS), 4 cases of TMZ-based chemotherapy, and 1 case of radiotherapy. Among the second-line strategies were 1 case of WS, 9 TMZ-based chemotherapy, 4 PCV-based chemotherapy, 1 fotemustine-based chemotherapy, and $1 \mathrm{BI}-$ based chemotherapy; among the third-line strategies were noted 7 cases of WS and 3 cases of radiotherapy; and among the fourth-line strategies were 3 cases of TMZ-, 1 PCV-, and 1 fotemustine-based chemotherapeutic treatments and 1 case of radiotherapy treatment.

Epilepsy. Seizure(s) was the first symptom in 20 of 22 cases. During the initial period, according to our database classification, seizure frequency was considered as occasionally (5 cases), monthly (9 cases), weekly (3 cases), and daily (3 cases). During the course of their epileptic disease, 8 patients were treated with 1 AED, 7 with 2 AEDs, 3 with 3 AEDs, 2 with 4 AEDs, and 1 with 5 AEDs. On the whole, 11 patients were treated with monotherapy and 10 with polytherapy.

The control of epilepsy differed according to the various treatment strategies. After close monitoring as the first-line strategy, the condition of $\sim 30 \%$ of the patients improved considerably with AED treatment only (EI: 3 patients, EII: 2 patients) and improved modestly, stabilized, or deteriorated in 70\% despite the AEDs (EIII: 5 patients, EIV: 7 patients). After TMZ-based chemother- 
TABLE 3: Summary of pretreatment data in 24 patients who underwent surgery*

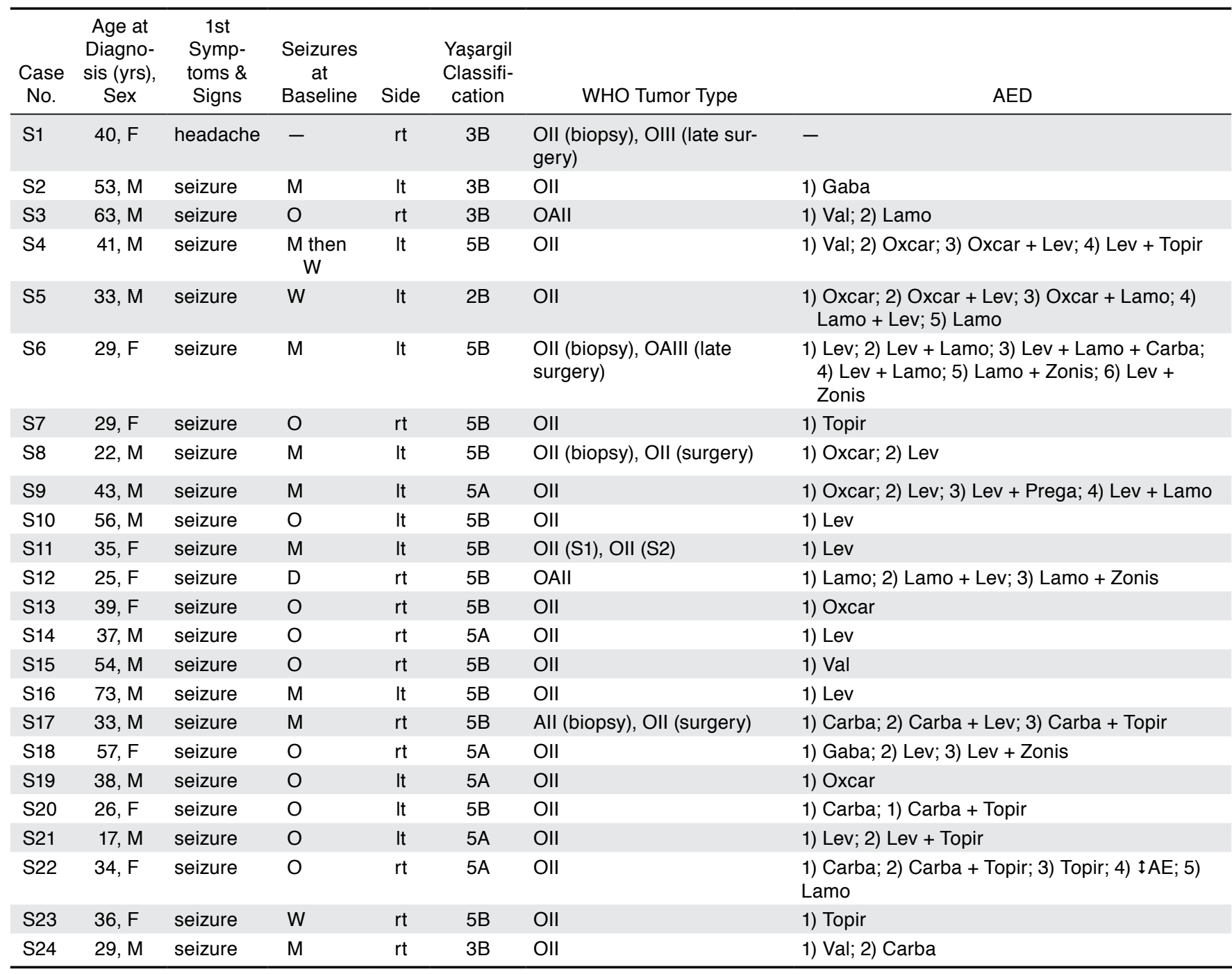

* IAE = AED stopped; biopsy = biopsy procedure first performed and then surgery; late surgery = surgery was performed after anaplastic transformation; OAII = oligoastrocytoma Type II; OAIII = oligoastrocytoma Type III; OIII = oligodendroglioma Type III; S1 = first surgery; S2 = second surgery; Zonis = zonisamide.

apy as the first-line strategy, all of the patients improved (EI: 3 patients, EII: 1 patient).

After a chemotherapy-based second-line strategy $(9$ TMZ-based, 4 PCV-based, 1 fotemustine-based, and 1 BI-based case), 10 patients (90\%) improved (6 patients gained 2 Engel classes and 4 patients gained 1 Engel class) and 1 stabilized. Three patients remained seizure free before and after the chemotherapy treatment.

The number of patients is too limited to report the results of radiotherapy as well as for the third and fourth lines of treatment.

\section{Surgical Population}

Clinical Data. The 24 patients who underwent surgery consisted of 14 men and 10 women, ranging in age from 17 to 73 years (mean 39 years). Twelve gliomas involved the dominant left hemisphere and 12 the nondom- inant right side. One patient reported intense headache, and none reported cognitive impairment. All preoperative neurological examinations were nondiagnostic.

Radiological Data. Pretherapeutic MR imaging revealed, according to the classification of Yaşargil et al. ${ }^{84}$ the following locations: 5 patients, Type 3B; 6 patients, Type 5A; and 13 patients, Type 5B.

Neuropathological Data. The neuropathological examination led to the diagnosis of 21 WHO Grade II oligodendrogliomas, 2 WHO Grade II oligoastrocytomas, and 1 WHO Grade II astrocytoma.

Oncological Strategies. From an oncological point of view, various strategies were considered. Among the firstline strategies were $12 \mathrm{WS}$ cases, 1 case of TMZ- and 1 PCV-based chemotherapeutic treatments, and 10 surgery cases. Among the second-line strategies were $1 \mathrm{WS}$ 
Epilepsy and insular Grade II gliomas

TABLE 4: Seizure evolution in patients who underwent surgery*

\begin{tabular}{|c|c|c|c|c|c|c|c|c|c|}
\hline $\begin{array}{l}\text { Case } \\
\text { No. }\end{array}$ & 1st Tx & $\begin{array}{c}\text { Seizure } \\
\text { Grade } \\
\text { After 1st Tx }\end{array}$ & 2nd Tx & $\begin{array}{l}\text { Seizure Grade } \\
\text { After } 2 \text { nd Tx }\end{array}$ & 3rd Tx & $\begin{array}{c}\text { Seizure Grade } \\
\text { After 3rd Tx }\end{array}$ & 4th $T x$ & $\begin{array}{c}\text { Seizure } \\
\text { Grade After } \\
\text { 4th Tx }\end{array}$ & FU \\
\hline S1 & $P C V \times 2$ & $\mathrm{EI}$ & $\mathrm{TMZ} \times 24$ & $\mathrm{El}$ & $\mathrm{WS} \rightarrow \mathrm{AT}$ & - & surgery & - & $\mathrm{RT}, \mathrm{F}, \mathrm{PC}$, \& death \\
\hline $\mathrm{S} 2$ & surgery & Ell & - & - & - & - & - & - & - \\
\hline S3 & surgery & $\mathrm{El}$ & WS & $\mathrm{EI}$ & - & - & - & - & - \\
\hline S4 & WS & EIV & surgery & $\begin{array}{l}\text { El }(1 \mathrm{yr}) \text { then } \\
\text { EIV }\end{array}$ & $\begin{array}{l}\mathrm{TMZ} \times \\
17 \rightarrow \mathrm{AT}\end{array}$ & EII then EIV & RT & Ell & $\mathrm{BI}, \mathrm{PC}$, \& death \\
\hline S6 & $\mathrm{TMZ} \times 1$ & EIV & RT & $\begin{array}{l}\text { EIl }(4 \mathrm{yrs}) \text { then } \\
\text { EIV }\end{array}$ & $\begin{array}{l}\mathrm{TMZ} \times \\
12 \rightarrow \mathrm{AT}\end{array}$ & EIV & surgery & $\mathrm{El}$ & $\begin{array}{l}\text { current: BI (after sur- } \\
\text { gery) }\end{array}$ \\
\hline S7 & surgery & $\begin{array}{l}\text { El }(2 \\
\text { years) } \\
\text { then ElI }\end{array}$ & - & - & - & - & - & - & current: WS \\
\hline S10 & WS & $\mathrm{EI}$ & surgery & $\mathrm{El}$ & - & - & - & - & current: WS \\
\hline $\mathrm{S} 11$ & S1 & $\begin{array}{l}\text { El ( } 7 \text { mos) } \\
\text { then ElII }\end{array}$ & $\mathrm{TMZ} \times 12$ & Ell & S2 & Ell & - & - & current: WS \\
\hline $\mathrm{S} 12$ & surgery & $\begin{array}{l}\text { EIII then } \\
\text { EIV }\end{array}$ & TMZ & $\begin{array}{l}\text { EIV then EIII } \\
\text { then EII then } \\
\text { EIV }\end{array}$ & RT & EIV then EIII & - & - & current: WS \\
\hline $\mathrm{S} 13$ & WS & Ell & surgery & $\mathrm{EI}$ & $\underset{8 \rightarrow A T}{T M Z}$ & $\mathrm{El}$ & $\mathrm{RT}$ & $\mathrm{El}$ & PCV, PC, \& death \\
\hline S14 & WS & Ell & surgery & $\mathrm{El}$ & - & - & - & - & current: WS \\
\hline $\mathrm{S} 15$ & WS & $\mathrm{EI}$ & surgery & $\mathrm{EI}, \downarrow \mathrm{AE}$ & - & - & - & - & current: WS \\
\hline $\mathrm{S} 16$ & surgery & Ell & - & - & - & - & - & - & current: WS \\
\hline $\mathrm{S} 21$ & WS & EIV & BBSFOP & $\mathrm{EI}$ & WS & EIV & surgery & $\begin{array}{l}\text { EIII and } \\
\text { then EIV }\end{array}$ & current: TMZ \\
\hline S22 & WS & Ell & $\mathrm{PCV} \times 6$ & Ell & RT & $\mathrm{El}$ & surgery & $\begin{array}{r}\text { El }(6 \mathrm{yrs}) \\
\text { then Ell }\end{array}$ & current: WS \\
\hline S23 & WS & EIV & surgery & $\mathrm{EI}$ & $\mathrm{TMZ} \times 12$ & $\mathrm{EI}$ & $\underset{4 \rightarrow A T}{P C V \times}$ & $\mathrm{EI}$ & RT, CE, PC, \& death \\
\hline S24 & S1 & $\begin{array}{r}\text { El }(2 \mathrm{yrs}) \\
\text { then Ell }\end{array}$ & $\begin{array}{l}\text { S2 (2nd } \\
\text { locali- } \\
\text { zation) }\end{array}$ & $\begin{array}{l}\text { El }(6 \text { mos }) \text { then } \\
\text { Ell }\end{array}$ & $\mathrm{TMZ} \times 3$ & $\mathrm{El}$ & RT & - & $\begin{array}{l}\text { PCV, CE, \& death } \\
\text { (sepsis) }\end{array}$ \\
\hline
\end{tabular}

* BBSFOP $=$ cisplatin + etoposide + vincristine + cyclophosphamide.

case, 7 TMZ cases, 1 PCV case, 1 radiotherapy case, and 10 surgery cases; among the third-line strategies were 7 TMZ cases, 2 radiotherapy cases, and 3 surgery cases; and among the fourth-line strategies were 1 PCV case, 6 radiotherapy cases, and 4 surgery cases.

Epilepsy. Seizure(s) was the first symptom in all surgical cases except 1 . During the initial period, according to our database classification, seizure frequency was con- sidered to be occasionally (11 cases), monthly ( 9 cases), weekly ( 2 cases), and daily ( 1 case). During the course of their epileptic disease, 10 patients were treated with a 1 AED, 5 with 2 AEDs, 4 with 3 AEDs, and 4 with 4 AEDs. On the whole, 11 patients were treated with monotherapy and 10 with polytherapy.

The course of epilepsy varied according to the different first-line strategies. After close monitoring as the 
TABLE 5: Summary of data on chemotherapy*

\begin{tabular}{|c|c|c|c|c|}
\hline Group & $\begin{array}{c}\text { Case } \\
\text { No. }\end{array}$ & $\begin{array}{l}\text { Seizure } \\
\text { Baseline }\end{array}$ & $\begin{array}{l}\text { Pre-CT } \\
\text { Engel } \\
\text { Grade }\end{array}$ & $\begin{array}{c}\text { Post-CT } \\
\text { Engel } \\
\text { Grade }\end{array}$ \\
\hline \multicolumn{5}{|l|}{ nonsurgical } \\
\hline \multicolumn{5}{|l|}{ first-line CT } \\
\hline \multirow[t]{4}{*}{ TMZ } & 1 & - & - & - \\
\hline & 6 & $\mathrm{O}$ & EIII & El \\
\hline & 7 & M & EIV & EII \\
\hline & 10 & M & EIII & $\mathrm{El}$ \\
\hline \multicolumn{5}{|l|}{ second-line CT } \\
\hline \multirow[t]{9}{*}{ TMZ } & 2 & $\mathrm{O}$ & EIII & $\mathrm{El}$ \\
\hline & 4 & M & EIV & Ell \\
\hline & 8 & $\mathrm{O}$ & El & $\mathrm{El}$ \\
\hline & 9 & W & El & El \\
\hline & 14 & M & EIV & EIII \\
\hline & 17 & $\mathrm{O}$ & Ell & $\mathrm{El}$ \\
\hline & 19 & $D$ & EIV & El \\
\hline & 21 & D & EIV & EIII \\
\hline & 22 & M & EIV & Ell \\
\hline \multirow[t]{4}{*}{ PCV } & 1 & - & - & - \\
\hline & 15 & M & EIII & EIII \\
\hline & 18 & M & EIV & El \\
\hline & 20 & $D$ & EIV & Ell \\
\hline fotemustine & 16 & $\mathrm{O}$ & EIII & EIV \\
\hline \multicolumn{5}{|l|}{$\begin{array}{l}\text { surgical } \\
\text { first-line CT }\end{array}$} \\
\hline TMZ & S6 & M & EIV & EIV \\
\hline $\begin{array}{l}\text { PCV } \\
\text { second-line CT }\end{array}$ & S1 & - & - & - \\
\hline \multirow[t]{5}{*}{ TMZ } & S1 & - & - & - \\
\hline & S5 & W & EIV & Ell \\
\hline & S8 & $\mathrm{O}$ & EIV & $\mathrm{El}$ \\
\hline & $\mathrm{S} 11$ & M & EIII & EII \\
\hline & $\mathrm{S} 12$ & D & EIII & Ell \\
\hline
\end{tabular}

* CT = chemotherapy.

first-line strategy, the condition of $\sim 40 \%$ of the patients improved considerably with AED treatment only (EI: 2 patients, EII: 3 patients) and modestly improved, stabilized, or deteriorated in 60\% (EIII: 1 patients, EIV: 6 patients) despite the AED treatment. After surgery as a first-line treatment, $90 \%$ of patients had improvement (EI: 7 patients, EII: 2 patients) and 10\% stabilized. After firstline TMZ-based chemotherapy, all the patients improved.

After second-line surgical treatment, $\sim 80 \%$ of patients improved (EI: 9 patients, EII: 0) and 20\% stabilized or deteriorated (EIII: 1 patient, EIV: 1 patient). After chemotherapy-based treatment (1 PCV and 7 TMZ), 8 of 8 patients had improvement (EI: 4 patients, EII: 4 patients).

The number of patients is too limited to report the results of radiotherapy and third- or fourth-line treatments.

\section{Discussion}

Our results confirm that seizures represent a key issue in GIIGs and that surgery and chemotherapy can be effective treatments.

\section{Seizures and Insular Gliomas}

The mechanism of epilepsy in patients with brain tumors is clearly multifactorial. ${ }^{13}$ Its incidence depends mainly on tumor type and location. The relation between a WHO Grade II glioma and an insular topography constitutes an association of negative factors. Indeed, patients with slowly progressive brain tumors (typically WHO Grade II gliomas) are known to frequently present with seizures in $>80 \%$ of cases, and intractable epilepsy is induced in at least $15 \%$ of cases. ${ }^{3,6,7,11,16-18,21,32,33,48,53,54,57,63,79,85}$

The participation of the insular cortex in epilepsy remains poorly understood because there are a limited number of works on the topic given the conceptual and surgical $22,23,27,37,45,60,66,69$ difficulties in studying this complex structure in the interface between the limbic system and the neocortex. The number of dedicated studies is very limited. ${ }^{16,20,22,23,27,30,43,45,58,59,66,69,84,86}$ Nevertheless, much data recently obtained via technical progress in the electrophysiological exploration of insular cortex ${ }^{43,66}$ appear to implicate this area in pharmacologically resistant seizures. ${ }^{1,52}$ Consequently, the frequency of seizures originating from the insular cortex is probably underestimated and often incorrectly attributed to mesiotemporal structures. ${ }^{2,14,17,20,30,35,43,58,59,82,83,86}$

In our series, epilepsy remains a major problem with 4 (9\%) of 41 patients with daily, $5(11 \%)$ of 41 with weekly, and 18 (42\%) of 41 with monthly seizures. Thus, the impact on quality of life seems very major. ${ }^{18,73}$

\section{Antiepileptic Drugs and Seizures}

The hepatic cytochrome P450 (CYP) isoenzyme system and glucuronyl transferase (GT) enzymes metabolize many drugs. The coadministration of enzyme-inducing AEDs with various treatments can lead to clinically relevant interactions by the induction or inhibition of enzymes. These interactions can cause insufficient tumor and seizure control or lead to unforeseen toxicity.

Enzyme-inducing AEDs, such as carbamazepine, oxcarbazepine, phenytoin, topiramate (high dose), and phenobarbital, can drastically reduce the serum concentration of associated drugs, which are substrates of the same enzymes, and notable levels and effects of antineoplastics $^{77,78}$ by compromising antitumor activity. Moreover, patients taking enzyme-inducing AEDs for $>2$ years (often the case for those with WHO GIIGs) and those > 40 years of age (not exceptional in this population) have significantly lower bone mineral density at clinically relevant fracture risk sites. ${ }^{62}$ In contrast, valproic acid is an enzyme inhibitor and may therefore lead to toxic levels of simultaneously administered chemotherapeutic agents, such as etoposide, platinum salts, or nitrosoureas, ${ }^{56}$ and might be responsible for an increasing hematotoxicity. ${ }^{9}$

For all of these reasons, enzyme-inducing AED use and, to a lesser degree, enzyme-inhibiting AEDs should be avoided in patients with WHO GIIGs-even more when 
chemotherapy is planned. It is therefore important to prefer AEDs not metabolized by the P450 system and with a good safety-profile, ${ }^{26,50,77}$ such as levetiracetam,${ }^{50}$ gabapentin,${ }^{78}$ pregabalin, ${ }^{55}$ lamotrigine, ${ }^{29,38}$ or lacosamide. ${ }^{19}$

It is licit to recommend 1) 1 or 2 successive nonenzyme-inducing AED monotherapies until the maximal doses recommended, unless there are signs of intolerance; and 2) before proceeding to a bitherapy, to avoid the more toxic coprescription of AEDs sharing the same primary mechanism of action. ${ }^{36,61} \mathrm{We}$ followed such recommendations with a majority of the non-enzyme-inducing AED mono- or bitherapies and the exceptional tritherapy in the present series. However, more properly designed clinical studies are warranted to raise the level of evidence for robust clinical recommendations. ${ }^{75}$

\section{Surgery and Seizures}

Tumors represent the primary pathology in 10-30\% of patients undergoing surgical treatment for chronic epilepsy. ${ }^{5}$ Seizures are more frequent in patients with WHO GIIGs and secondary malignant gliomas than other primary tumors of the brain. ${ }^{67}$ The frequency of seizures seems to evolve in parallel with tumor growth. ${ }^{81}$ It was verified in the present retrospective series that in a majority of cases, an increase in seizure frequency is correlated with significant tumor growth in cases not transformed (still Grade II).

Insular WHO GIIGs seem to represent a specific etiology of intractable epilepsy in $>50 \%$ of cases $^{24}$ compared with other locations of the same pathology in which drug-resistant seizures were seen in $\sim 15 \%$ of cases. ${ }^{3,6,7,11,13,16,18,21,32,33,41,48,53,54,57,63,79,85}$ Patients with drugresistant epilepsy and temporal lobe tumors should undergo evaluation in dedicated oncology and epilepsy surgery programs. ${ }^{46}$

Few published studies have considered surgery in the control of seizures due to insular tumors. This control seems to be reported in $\sim 80$ to $90 \%$ of cases of surgical tumorectomy associated with perilesional cortical resection with or without the removal of mesiotemporal structures, ${ }^{66,70,84,86}$ while preserving or even improving-as with tumors in locations other than the insula-quality of life and survival. ${ }^{7,41,70}$ Even subtotal resection can result in good seizure control. ${ }^{80}$ In the present series after surgery as a first-line strategy, $\sim 90 \%$ of patients had improvement and $10 \%$ stabilized. Furthermore, after surgery as a second-line strategy, $\sim 80 \%$ of patients had improvement and $10 \%$ stabilized. These results perfectly correspond with findings that were first published. ${ }^{24}$

Note that in our series, the indications for resection were gradually modified. Ten years ago, chemotherapy or radiotherapy was begun after a simple biopsy procedure. As surgical techniques have advanced, especially intraoperative functional mapping with cortical and subcortical stimulations, indications for surgery have become more numerous. At present, a first-intention resection to functional and anatomical limits (within the anterior perforating substance and the posterior part of the dominant insula) is discussed. Indications are based more on oncological than epileptological reasons. Intraoperative electrocorticography is not used. Resection is pushed until the functional boundaries, which are identified using corticosubcortical electrostimulation. As a consequence, even if a seizure focus was detected by electrocorticography beyond these limits, it would not have been possible to remove it for functional reasons. ${ }^{23}$ In addition, no specific part of the insula was recognized as being more specifically involved in the epileptogenesis. The effect on seizures seems to be due more to the extent of surgery. ${ }^{13}$ During the postsurgical period, antiepileptic treatment is pursued. In cases of complete surgery and an absence of seizures, we recommend a progressive decrease in and then arrest of treatment 1 year after surgery. For the opposite situation (incomplete surgery) - except in patients with a long seizure-free period-we usually recommend pursuit of the treatment and most often a monotherapy at the lowest level.

\section{Chemotherapy and Seizures}

For growing nonsurgical tumors (or following an incomplete resection), when AEDs no longer control seizures or when other symptoms become more marked (cognitive impairment, focal signs), direct tumor treatment as opposed to symptom treatment should be considered. Among these, chemotherapy has taken a more and more important role in the last few years and should be systematically discussed. Many theoretical arguments, such as subnormal blood-brain or blood-tumor barrier or low proliferation indices, must be considered against chemotherapy's potential efficiency for this type of tumor. Note that the first and only published randomized Phase III trial of chemotherapy for low-grade gliomas was conducted by the Southwestern Oncology Group. Radiotherapy alone was compared with radiotherapy plus lomustine chemotherapy after subtotal/partial surgery or biopsy. No benefit was demonstrated, and the trial was prematurely terminated.

Nevertheless, we have more and more data allowing us to propose this treatment in symptomatic patients. MacDonald et al. ${ }^{49}$ have been the first, in a study of aggressive oligodendrogliomas, to suggest the possibility of an objective response in low-grade tumors. Six years later, Mason et al. ${ }^{51}$ noted 9 of 9 responders $(8$ patients at presentation and 1 patient at a recurrence after radiotherapy) treated with a PCV regimen while Soffietti et al. ${ }^{71}$ reported on 13 of 13 stabilized or responsive patients treated with PCV. More recently, Buckner et al. ${ }^{15}$ have described a series of 29 patients treated with PCV and noted an objective response in $28 \%$, but chemotherapy was immediately followed by radiotherapy in this series. Brada et al..$^{10}$ have treated 10 patients with TMZ for newly diagnosed oligodendrogliomas and observed 2 partial responses and 3 minor responses. The multicentric study described by Quinn et al. ${ }^{65}$ was based on TMZ chemotherapy in 46 patients with tumor progression, a majority with astrocytomas and 14 patients pretreated with radiotherapy and chemotherapy. Sixty-one percent of objective responses were noted. Progression-free survival for the entire group was 22 months. Seventy-six percent were in a period of progression-free survival at 12 months from the beginning of treatment. Hoang-Xuan et al. ${ }^{42}$ have reported their experience treating 60 patients according to a conventional TMZ schedule $\left(200 \mathrm{mg} / \mathrm{m}^{2} /\right.$ day for 5 days 
every 28 days). The median number of delivered chemotherapy cycles was 11 . More than one-half of the patients had clinical improvement. A radiologically demonstrated objective response was noted in one-third of the cases. Only $8 \%$ of the patients were considered to be in tumor progression during the treatment period. The only factor correlated with the treatment response was the loss of chromosome 1p. Results followed suit for Stege et al. ${ }^{72}$ who delivered PCV chemotherapy treatment for lowgrade gliomas. He treated 16 patients with a new diagnosis and 5 patients at recurrence and observed 13 and 3 respective responses with a median time to disease progression up to 24 months. Frenay et al. ${ }^{31}$ have also reported their PCV experience in 10 patients with pure WHO Grade II astrocytomas, with clear clinical improvement in all cases. Sixty percent of the patients became seizure free at the end of the treatment despite the fact that pharmacologically resistant epilepsy had developed in all patients before chemotherapy. Finally, Lebrun et al. ${ }^{47}$ have reported the outcome in 33 consecutive patients with a pure WHO GIIG. Ninety percent of these patients remained progression free at 1 year after treatment with very good long-term results from an epileptic point of view. In the present study, 26 patients were treated with chemotherapy as a first- or second-line treatment for progressive tumors: TMZ was used in 19 cases, PCV in 6 cases, and fotemustine in 1 case. A major improvement in the frequency of seizures (gain of 2 Engel classes) was observed in 11 cases while the AEDs were not modified. A clear improvement (gain of 1 Engel class) was observed in 5 cases. An absence of modification or an escalation in seizure frequency was noticed in 3 cases. Six patients did not present with any seizure before or after chemotherapy. Notably, chemotherapy led to excellent results from an epileptic point of view in $16(84.2 \%)$ of 19 cases.

We have just seen that the historic association of PCV or more recent monotherapy with TMZ can provide clear symptomatic improvements in epilepsy due to insular GIIG despite the fact that few authors have specifically considered this point at all ${ }^{10,42}$ and even more rarely in detail..$^{31,47}$ Data in the literature remain especially exceptional for an insular location. Note that the tolerance of this treatment is not perfect. The PCV association has a cumulative hematological toxicity, rendering the administration of $>4$ or 6 courses difficult without serious adverse events. The peripheral neurological risk of the vincristine or the risk of lung fibrosis with the lomustine should not to be neglected. Patients frequently report an intense asthenia or a loss of weight. Gonadic toxicity also seems frequent.

The prescription of TMZ with various modalities ${ }^{12}$ would eventually be more adapted to this type of tumor without the cumulative hematological toxicity despite very prolonged treatments (24 months and sometimes more). It will be necessary to consider the risk of lymphocytopenia, especially with continuous treatment plans, and in some cases a preventive treatment of opportunistic infections, notably pneumocystosis. ${ }^{34}$ The risk of cutaneous eruption and even of liver toxicity should not be underscored, and no data are available concerning potential gonadic toxicity.

Finally, it is reasonable to think that chemotherapy is able to improve the quality of life..$^{8,10,15,42,47,72}$ In practice, our present tendency is to favor this type of treatment as a first-line strategy for nonoperable tumors or on the relapse of gliomas incompletely removed, in case of clinical (epileptological) and/or significant radiological progression. Our aims are as follows: 1) clear clinical efficiency translated into a relief of seizures, a decrease in AEDs (number and dosage), better social implications, and thus an improvement in quality of life; 2) the opportunity to envisage subtotal or total resection when complete removal was not possible during the first resection, thanks to shrinkage induced by the chemotherapy ${ }^{25}$ ( 6 patients in this series [Cases S1, S6, S8, S18, S21, and S22] have had such a benefit from surgery after 1 or 2 lines of chemotherapy); and 3) the ability to delay radiotherapy because of its potential neurocognitive side effects, especially when delivered to large volumes and functional areas. ${ }^{73,74}$

It is nevertheless imperative to confirm these hypotheses, to set up clinical trials, and to associate with them a number of ancillary works connected to biological, pathological, radiological, epileptological, functional, neurocognitive, and economic questions.

We would have liked to write an identical paragraph concerning radiotherapy and, more precisely, the impact of radiotherapy on seizures due to an insular GIIG. Regrettably, the data in the literature ${ }^{68}$ and the cases in the present series (in which radiotherapy was kept for progression after surgery and/or chemotherapy) are rare. Nevertheless, they have allowed us, contrary to authors of the majority of published articles, to obtain a "pure" and unique vision concerning the impact of a specific treatment (chemotherapy) on a specific symptom (seizure) at a precise location (insula).

\section{Conclusions}

The analysis of the literature and this unique series allowed us to consolidate the concept that surgery, despite any technical difficulties, could be indicated in pharmacoresistant epilepsy due to insular glioma independently of the oncological indications. We also demonstrated that chemotherapy (TMZ or PCV) could also be an effective weapon against seizures. It is obvious that a combined version of these 2 therapeutic modalities must be used in daily practice. It requires close collaboration between neurosurgeons and neurooncologists and an adaptation of strategies to each individual case for optimal preservation, as long as possible, of the quality of life. Finally, progress-not just in terms of improved surgical techniques and new drug development - should be based on a better systematic longitudinal collection and an analysis of both neurocognition parameters and quality of life with new adapted scales.

\section{Disclaimer}

The authors report no conflict of interest concerning the materials or methods used in this study or the findings specified in this paper.

\section{References}

1. Augustine JR: Circuitry and functional aspects of the insular lobe in primates including humans. Brain Res Brain Res Rev 22:229-244, 1996

2. Aziz Q, Anderson JC, Valind S, Sundin A, Hamdy S, Jones 
AK, et al: Identification of human brain loci processing oesophageal sensation using positron emission tomography. Gastroenterology 113:50-59, 1997

3. Bartolomei JC, Christopher S, Vives K, Spencer DD, Piepmeier JM: Low-grade gliomas of chronic epilepsy: a distinct clinical and pathological entity. J Neurooncol 34:79-84, 1997

4. Bauchet L, Rigau V, Mathieu-Daudé H, Figarella-Branger D, Hugues D, Palusseau L, et al: A French brain tumor data bank: methodology and first results on 10,000 cases. J Neurooncol 84:189-199, 2007

5. Bauer R, Dobesberger J, Unterhofer C, Unterberger I, Walser G, Bauer G, et al: Outcome of adult patients with temporal lobe tumours and medically refractory focal epilepsy. Acta Neurochir (Wien) 149:1211-1216, 2007

6. Berger MS: Functional mapping-guided resection of lowgrade gliomas. Clin Neurosurg 42:437-452, 1995

7. Berger MS, Ghatan S, Haglund MM, Dobbins J, Ojemann GA: Low-grade gliomas associated with intractable epilepsy: seizure outcome utilizing electrocorticography during tumor resection. J Neurosurg 79:62-69, 1993

8. Byrne TN: Response of low-grade oligodendroglial tumors to temozolomide. J Neurooncol 70:279-280, 2004

9. Bourg V, Lebrun C, Chichmanian RM, Thomas P, Frenay M: Nitroso-urea-cisplatin-based chemotherapy associated with valproate: increase of hematologic toxicity. Ann Oncol 12:217-219, 2001

10. Brada M, Viviers L, Abson C, Hines F, Britton J, Ashley S, et al: Phase II study of primary temozolomide chemotherapy in patients with WHO II grade gliomas. Ann Oncol 14:1715-1721, 2003

11. Britton JW, Cascino GD, Sharbrough FW, Kelly PJ: Lowgrade neoplasms and intractable partial epilepsy: efficacy of surgical treatment. Epilepsia 35:1130-1135, 1994

12. Brock CS, Newlands ES, Wedge SR, Bower M, Evans H, Colquhoun I, et al: Phase I trial of temozolomide using an extended continuous oral schedule. Cancer Res 58:4363-4367, 1998

13. Brogna C, Gil Robles S, Duffau H: Brain tumors and epilepsy. Expert Rev Neurother 8:941-955, 2008

14. Buchel C, Morris J, Dolan RJ, Friston KJ: Brain systems mediating aversive conditioning: an event related fMRI study. Neuron 20:947-957, 1998

15. Buckner JC, Gesme D Jr, O'Fallon JR, Hammack JE, Stafford S, Brown PD, et al: Phase II trial of procarbazine, lomustine and vincristine as initial therapy for patients with low-grade oligodendroglioma or oligoastrocytoma: efficacy and associations with chromosomal abnormalities. J Clin Oncol 21:251-255, 2003

16. Cascino GD: Epilepsy and brain tumors: implication for treatment. Epilepsia 31:37-44, 1990

17. Cascino GD, Karnes WE: Gustatory and second sensory seizures associated with lesions in the insular cortex seen on magnetic resonance imaging. J Epilepsy 3:185-187, 1990

18. Chang EF, Potts MB, Keles GE, Lamborn Kr, Chang SM, Barbaro NM, et al: Seizure characteristics and control following resection in 332 patients with low-grade gliomas. J Neurosurg 108: 227-235, 2008

19. Cross SA, Curran MP: Lacosamide: in partial-onset seizures. Drugs 69:449-459, 2009

20. Cukiert A, Forster C, Andrioli MS, Frayman L: Insular epilepsy. Similarities to temporal lobe epilepsy. Case report. Arq Neuropsiquiatr 56:126-128, 1998

21. Devaux B, Chassoux F, Landre E, Turak B, Daumas-Duport C, Chagot D, et al: Chronic intractable epilepsy associated with a tumor located in the central region: functional mapping data and postoperative outcome. Stereotact Funct Neurosurg 69:229-238, 1997

22. Duffau H, Bauchet L, Lehericy S, Capelle L: Functional compensation of the left dominant insula for language. Neuroreport 12:2159-2163, 2001

23. Duffau H, Capelle L, Lopes M, Faillot T, Sichez JP, Fohanno $\mathrm{D}$ : The insular lobe: physiopathological and surgical consid- erations. Neurosurgery 47:801-811, 2000

24. Duffau H, Capelle L, Lopes M, Bitar A, Sichez JP, van Effenterre R: Medically intractable epilepsy from insular low-grade gliomas: improvement after an extended lesionectomy. Acta Neurochir (Wien) 144:563-573, 2002

25. Duffau H, Taillandier L, Capelle L: Radical surgery after chemotherapy: a new therapeutic strategy to envision in grade II glioma. J Neurooncol 80:171-176, 2006

26. Dupont S: [Epilepsy and brain tumors.] Rev Neurol (Paris) 164:517-522, 2008 (Fr)

27. Ebeling U, Kothbauer K: Circumscribed low grade astrocytomas in the dominant opercular and insular region: a pilot study. Acta Neurochir (Wien) 132:66-74, 1995

28. Engel J Jr: Alternative therapy, in Engel J Jr (ed): Seizures and epilepsy. Philadelphia, PA: FA Davis, 1990, pp 443-474

29. Fadul CE, Meyer LP, Jobst BC, Cornell CJ, Lewis LD: Agranulocytosis associated with lamotrigine in a patient with lowgrade glioma. Epilepsia 43:199-200, 2002

30. Fiol ME, Leppik IE, Mireles R, Maxwell R: Ictus emeticus and the insular cortex. Epilepsy Res 2:127-131, 1988

31. Frenay MP, Fontaine D, Vandenbos F, Lebrun C: First-line nitrosourea-based chemotherapy in symptomatic non-resectable supratentorial pure low-grade astrocytomas. Eur J Neurol 12:685-690, 2005

32. Fried I: Management of low-grade gliomas: results of resections without electrocorticography. Clin Neurosurg 42:453463, 1995

33. Fried I, Kim JH, Spencer DD: Limbic and neocortical gliomas associated with intractable seizures: a distinct clinicopathological group. Neurosurgery 34:815-824, 1994

34. Gajewski TF: Temozolomide for melanoma: new toxicities and new opportunities. J Clin Oncol 22:580-581, 2004

35. Ghaem O, Mellet E, Crivello F, Tzourio N, Mazoyer B, Berthoz A, et al: Mental navigation along memorized routes activates the hippocampus precuneus and insula. Neuroreport 8:739-744, 1997

36. Glauser T, Ben-Menachem E, Bourgeois B, Cnaan A, Chadwick D, Guerreiro C, et al: ILAE treatment guidelines: evidence-based analysis of antiepileptic drug efficacy and effectiveness as initial monotherapy for epileptic seizures and syndromes. Epilepsia 47:1094-1120, 2006

37. Haglund MM, Berger MS, Kunkel DD, Franck JE, Ghatan S, Ojemann GA: Changes in gamma-aminobutyric acid and somatostatin in epileptic cortex associated with low-grade gliomas. J Neurosurg 77:209-216, 1992

38. Hennessy MJ, Wiles CM: Lamotrigine encephalopathy. Lancet 347:974-975, 1996

39. Hildebrand J: Management of epileptic seizures. Curr Opin Oncol 16:314-317, 2004

40. Hildebrand J, Lecaille C, Perennes J, Delattre JY: Epileptic seizures during follow up of patients treated for primary brain tumors. Neurology 65:212-215, 2005

41. Hiremath GK, Bingaman WE, Prayson RA, Nair D: Oligoastrocytoma presenting with intractable epilepsy. Epileptic Disord 9:315-322, 2007

42. Hoang-Xuan K, Capelle L, Kujas M, Taillibert S, Duffau H, Lejeune J, et al: Temozolomide as initial treatment for adults with low grade oligodendrogliomas or oligoastrocytomas and correlation with chromosome 1p deletions. J Clin Oncol 22:3133-3138, 2004

43. Isnard J, Guenot M, Ostrowsky K, Sindou M, Mauguiere F: The role of the insular cortex in temporal lobe epilepsy. Ann Neurol 48:614-623, 2000

44. Kirkpatrick PJ, Honavar M, Janota I, Poltrey CE: Control of temporal lobe epilepsy following en bloc resection of lowgrade tumors. J Neurosurg 78:19-25, 1993

45. Lang FF, Olansen NE, DeMonte F, Gokaslan ZL, Holland EC, Kalhorn C, et al: Surgical resection of intrinsic insular tumors: complication avoidance. J Neurosurg 95:638-650, 2001

46. Laws ER Jr, Taylor WF, Clifton MB, Okazaki H: Neurosur- 
gical management of low-grade astrocytomas of the cerebral hemispheres. J Neurosurg 61:665-673, 1984

47. Lebrun C, Fontaine D, Bourg V, Ramaioli A, Chanalet S, Vandenbos F, et al: Treatment of newly diagnosed symptomatic pure low-grade oligodendrogliomas with PCV chemotherapy. Eur J Neurol 14:391-398, 2007

48. Lombardi D, Marsh R, De Tribolet N: Low grade glioma in intractable epilepsy: lesionectomy versus epilepsy surgery. Acta Neurochir Suppl 68:70-74, 1997

49. MacDonald DR, Cascino TL, Schold SC Jr, Cairncross JG: Response criteria for phase II studies of supratentorial malignant glioma. J Clin Oncol 8:1277-1280, 1990

50. Maschio M, Dinapoli L, Zarabia A, Jandolo B: Issues related to the pharmacological management of patients with brain tumours and epilepsy. Funct Neurol 21:15-19, 2006

51. Mason WP, Krol GS, DeAngelis LM: Low grade oligodendroglioma responds to chemotherapy. Neurology 46:203-207, 1996

52. Mesulam MM, Mufson E: The insula of Reil in man and monkey, in Jones GE, Peters AA (eds): Cerebral Cortex. New York: Plenum Press, pp 179-225, 1985

53. Morris HH, Estes ML, Gilmore R, Van Ness PC, Barnett GH, Turnbull J: Chronic intractable epilepsy as the only symptom of primary brain tumor. Epilepsia 34:1038-1043, 1993

54. Morris HH, Matkovic Z, Estes ML, Prayson RA, Comair YG, Turnbull J, et al: Ganglioglioma and intractable epilepsy: clinical and neurophysiologic features and predictors of outcome after surgery. Epilepsia 39:307-313, 1998

55. Novy J, Stupp R, Rossetti AO: Pregabalin in patients with primary brain tumors and seizures: a preliminary observation. Clin Neurol Neurosurg 111:171-173, 2009

56. Oberndorfer S, Piribauer M, Marosi C, Lahrmann H, Hitzenberger P, Grisold W: P450 enzyme inducing and non-enzyme inducing antiepileptics in glioblastoma patients treated with standard chemotherapy. J Neurooncol 72:255-260, 2005

57. Olivier A, Lacerte D: Epilepsy and benign gliomas, in Apuzzo MLJ (ed): Low Grade Glioma. New York: AANS, 1995, pp 347-379

58. Ostrowsky K, Isnard J, Ryvlin P, Guénot M, Fisher C, Mauguiere F: Functional mapping of the insular cortex: clinical implication in temporal lobe epilepsy. Epilepsia 41:681-686, 2000

59. Penfield W, Faulk ME Jr: The insula: further observations on its function. Brain 78:445-470, 1955

60. Penfield W, Jasper H: Epilepsy and the Functional Anatomy of the Human Brain. Boston: Little Brown, 1954

61. Perucca E, Hedges A, Makki KA, Ruprah M, Wilson JF, Richens A: A comparative study of the relative enzyme inducing properties of anticonvulsant drugs in epileptic patients. 1984. Br J Clin Pharmacol 58:S854-S863, 2004

62. Petty SJ, Paton LM, O’Brien TJ, Makovey J, Erbas B, Sambrook P, et al: Effect of antiepileptic medication on bone mineral measures. Neurology 65:1358-1365, 2005

63. Piepmeier JM: Observations on the current treatment of lowgrade astrocytic tumors of the cerebral hemispheres. J Neurosurg 67:177-181, 1987

64. Pilcher WH, Silbergeld DL, Berger MS, Ojemann GA: Intraoperative electrocorticography during tumor resection: impact on seizure outcome in patients with gangliogliomas. J Neurosurg 78:891-902, 1993

65. Quinn JA, Reardon DA, Friedman AH, Rich JN, Sampson $\mathrm{JH}$, Provenzale JM, et al: Phase II trial of temozolomide in patients with progressive low-grade glioma. J Clin Oncol 21:646-651, 2003

66. Roper SN, Lévesque MF, Sutherling WW, Engel J Jr: Surgical treatment of partial epilepsy arising from the insular cortex. J Neurosurg 79:266-269, 1993

67. Rosati A, Tomassini A, Pollo B, Ambrosi C, Schwarz A, Padovani A, et al: Epilepsy in cerebral glioma: timing of appearance and histological correlations. J Neurooncol 93: 395-400, 2009
68. Shankar A, Rasjshekhar V, Shankar A, Rajshekhar V: Radiological and clinical outcome following stereotactic biopsy and radiotherapy for low grade insular astrocytoma. Neurol India 51:503-506, 2003

69. Silfvenius H, Gloor P, Rasmussen T: Evaluation of insular ablation in surgical treatment of temporal lobe epilepsy. Epilepsia 5:307-320, 1964

70. Simon M, Neuloh G, von Lehe M, Meyer B, Schramm J: Insular gliomas: the case for surgical management. J Neurosurg 110:685-695, 2009

71. Soffietti R, Ruda R, Bradac GB, Schiffer D: PCV chemotherapy for recurrent oligodendrogliomas and oligoastrocytomas. Neurosurgery 43:1066-1073, 1998

72. Stege EM, Kros JM, De Bruin HG, Enting RH, Van Heuvel I, Looijenga LH, et al: Successful treatment of low grade oligodendroglial tumors with a chemotherapy regimen of procarbazine, lomustine and vincristine. Cancer 103:802-809, 2005

73. Taphoorn MJ: Neurocognitive sequelae in the treatment of low-grade gliomas. Semin Oncol 30 (19 Suppl):45-48, 2003

74. Taphoorn MJ, Klein M: Cognitive deficits in adult patients with brain tumours. Lancet Neurol 3:159-168, 2004

75. Tibussek D, Distelmaier F, Schönberger S, Göbel U, Mayatepek E: Antiepileptic treatment in paediatric oncology-an interdisciplinary challenge. Klin Padiatr 218:340-349, 2006

76. Vanaclocha V, Saiz-Sapena N, Garcia-Casasola C: Surgical treatment of insular gliomas. Acta Neurochir (Wien) 139:1126-1135, 1997

77. Vecht CJ, Wagner GL, Wilms EB: Interactions between antiepileptic and chemotherapeutic drugs. Lancet Neurol 2:404409, 2003

78. Vecht CJ, Wagner GL, Wilms EB: Treating seizures in patients with brain tumors: Drug interactions between antiepileptic and chemotherapeutic agents. Semin Oncol 30 (6 Suppl 19):49-52, 2003

79. Villemure JG, De Tribolet N: Epilepsia in patients with central nervous system tumors. Curr Opin Neurol 9:424-428, 1996

80. von Lehe M, Lutz M, Kral T, Schramm J, Elger CE, Clusmann $\mathrm{H}$ : Correlation of health-related quality of life after surgery for mesial temporal lobe epilepsy with two seizure outcome scales. Epilepsy Behav 9:73-82, 2006

81. Wick W, Menn O, Meisner C, Steinbach J, Hermisson M, Tatagiba M, et al: Pharmacotherapy of epileptic seizures in glioma patients: who, when, why and how long? Onkologie 28:391-406, 2005

82. Wieser HG: Electroclinical Features of the Psychomotorseizure. Stuttgart: Gustav Fisher, 1983

83. Xu X, Fukuyama H, Yazawa S, Mima T, Hanakawa T, Magata $\mathrm{Y}$, et al: Functional localization of pain perception in the human brain studied by PET. Neuroreport 8:555-559, 1997

84. Yaşargil MG, von Ammon K, Cavazos E, Doczi T, Reeves JD, Roth P: Tumours of the limbic and paralimbic systems. Acta Neurochir (Wien) 118:40-52, 1992

85. Zentner J, Hufnagel A, Wolf HK, Ostertun B, Behrens E, Campos MG, et al: Surgical treatment of neoplasms associated with medically intractable epilepsy. Neurosurgery 41:378-387, 1997

86. Zentner J, Meyer B, Stangl A, Schramm J: Intrinsic tumors of the insula: a prospective study of 30 patients. J Neurosurg 85:263-271, 1996

Manuscript submitted April 14, 2009.

Accepted June 9, 2009.

Address correspondence to: Luc Taillandier, M.D., Ph.D., Neurooncology Unit, Department of Neurology, Hôpital Central, Centre Hopitalier Universitaire de Nancy, 29 Avenue du Marechal de Lattre de Tassigny, 54035 Nancy, France. email: 1.taillandier@chu-nancy.fr. 